\title{
Measurement and Control of Glass Feedstocks
}

Final Report

\author{
Arel Weisberg (PI) \\ Joe Craparo \\ Robert De Saro (PI) \\ ERCo \\ Energy Research Co. \\ 2571-A Arthur Kill Road \\ Staten Island, NY 10309 \\ (718) 608-8788 \\ rdesaro@er-co.com
}

15 April 2007

\author{
Prepared for \\ The U.S. Department of Energy \\ Under Award Number DE-FC36-01ID14030
}




\section{Disclaimer}

Any opinions, findings, and conclusions or recommendations expressed in this material are those of the authors and do not necessarily reflect the views of the Department of Energy. 


\section{Acknowledgments}

This material is based upon work supported by the U S. Department of Energy under Award Number DE-FC36-01ID14030.

The authors are greatly appreciative of the guidance, support, and encouragement provided by the following:

- Elliot Levine (DOE - Industrial Technologies Program; Glass Program)

- Cheryl Richards (Market Development Manager - PPG Industries, Inc.)

- David Bivins (Glass Modeling - PPG Industries, Inc.)

- Tom Fenton (Vice President of Manufacturing - Fenton) 


\section{Executive Summary}

ERCo has developed a laser-based technology for rapid compositional measurements of batch, real-time sorting of cullet, and in-situ measurements of molten glass. This technology, termed LIBS (Laser Induced Breakdown Spectroscopy) can determine whether or not the batch was formulated accurately in order to control glass quality. It can also be used to determine if individual batch ingredients are within specifications. In the case of cullet feedstocks, the sensor can serve as part of a system to sort cullet by color and ensure that it is free of contaminants. In-situ compositional measurements of molten glass are achieved through immersing a LIBS probe directly into the melt in a glass furnace. This technology has been successfully demonstrated in ERCo's LIBS laboratory for batch analysis, cullet sorting, and glass melt measurements. A commercial batch analyzer has been operating in a PPG fiberglass plant since August 2004.

LIBS utilizes a highly concentrated laser pulse to rapidly vaporize and ionize nanograms of the material being studied. As this vapor cools, it radiates light at specific wavelengths corresponding to the elemental constituents (e.g. silicon, aluminum, iron) of the material. The strengths of the emissions correlate to the concentrations of each of the elemental constituents. By collecting the radiated light with a spectrometer capable of resolving and measuring these wavelengths, the elemental composition of the sample is found. 


\section{Table of Contents}

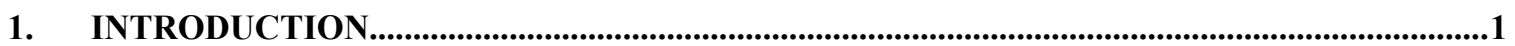

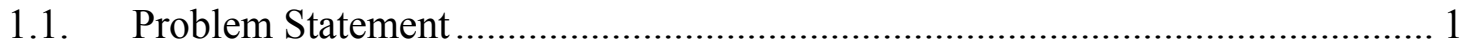

1.2. Teaming members............................................................................... 1

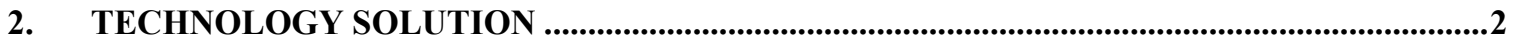

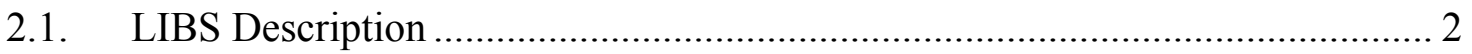

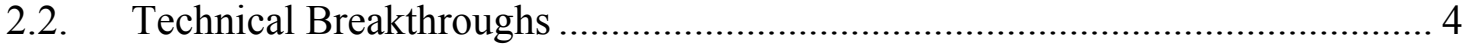

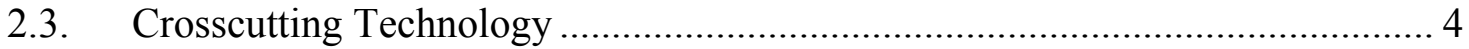

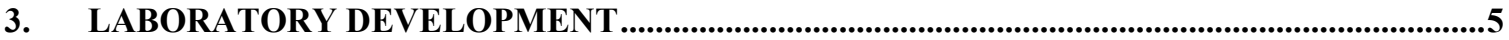

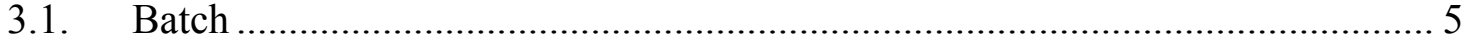

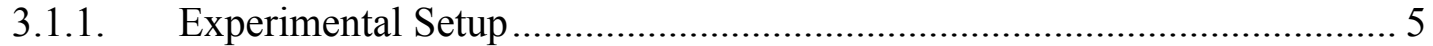

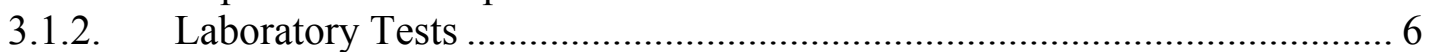

3.2. Cullet Sorting ........................................................................................ 8

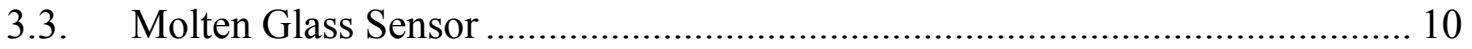

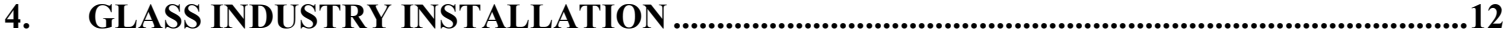

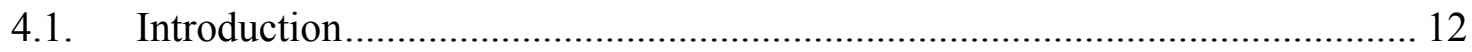

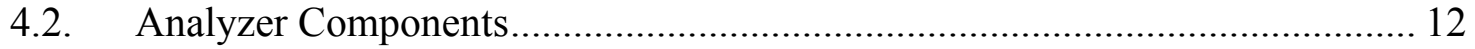

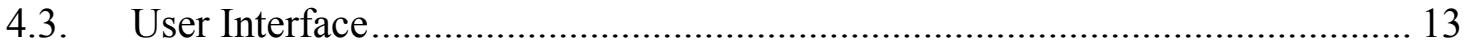

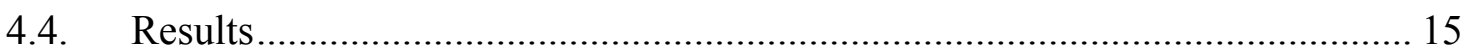

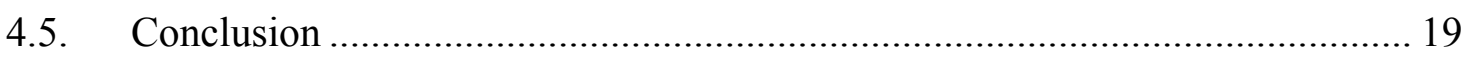

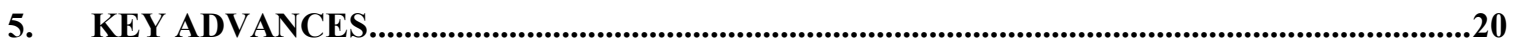

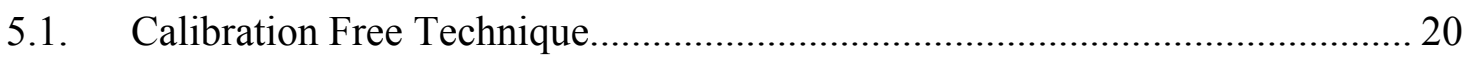

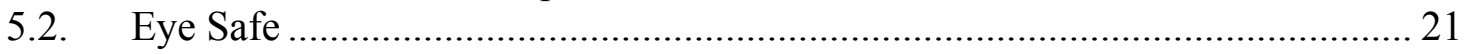

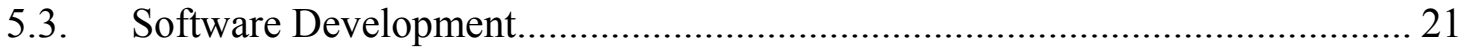

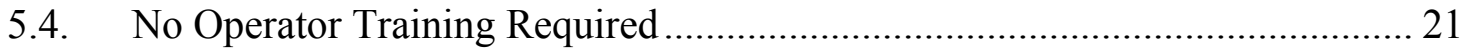

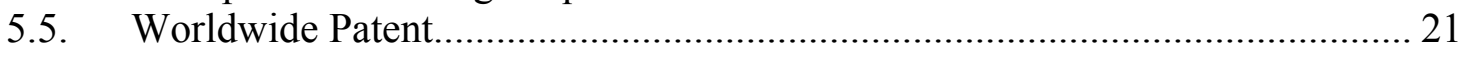

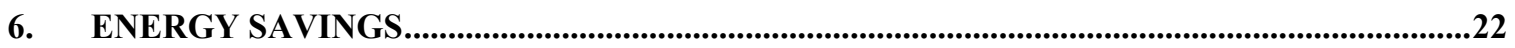

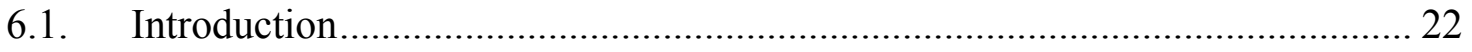

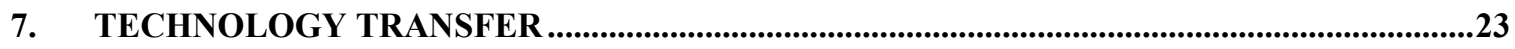

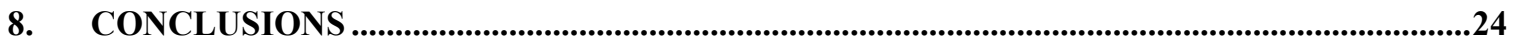




\section{Table of Figures}

Figure 1 - Schematic of Batch Analyzer................................................................... 2

Figure 2 - LIBS Spectra ......................................................................................... 3

Figure 3 -Photograph of Experimental Setup for Laboratory Ulexite Tests..................... 5

Figure 4 -Cabinet for LIBS Tests on Ulexite........................................................... 6

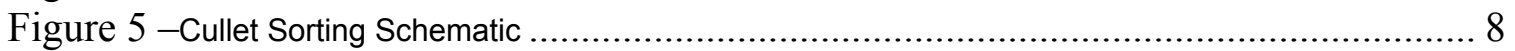

Figure 6 -Samples of Cullet and Contaminants (Left) and a Photograph of a LIBS Spark on Rotating Cullet (Right) .............................................................................. 9

Figure 7 - Photograph of ERCo Batch Analyzer Equipment in PPG Chester Plant......... 12

Figure 8 - Close up of Batch Sample Chamber ......................................................... 13

Figure 9 - PPG Production Manager Kevin Streicher Placing a Sample into the Chamber for Analysis (Left) and Batch House Supervisor Phil Gibson Prepares a Ulexite Sample for Analysis (Right) ............................................................................. 13

Figure 10 - ERCo's LIBS Software Control Panel ........................................................ 14

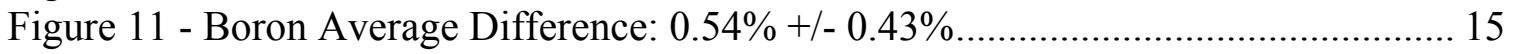

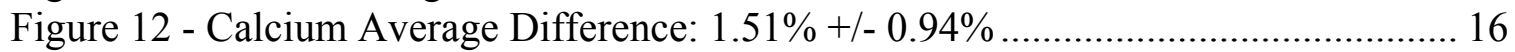

Figure 13 - Sodium Average Difference: $2.75 \%+/-1.54 \%$.......................................... 16

Figure 14 - Silicon Average Difference: 4.98\% +/- 4.02\% ......................................... 16

Figure 15 - Magnesium Average Difference: 4.06\% +/- 2.72\% ................................... 17

Figure 16 - Strontium Average Difference: 0.026\% +/- 0.018\% .................................... 17

Figure 17 - Aluminum Average Difference: 0.007\% +/- 0.004\% ................................. 18

Figure 18 - Iron Average Difference: $0.003 \%$ +/- 0.002\% ......................................... 18 


\section{Table of Tables}

Table 1 - Summary of Cullet Sorting Test with Silicon Detector Simulation ................... 9

Table 2 - LIBS Results on Molten Glass ...................................................................... 11

Table 3 - Results Summary from Blind Tests........................................................ 18 


\section{Introduction}

\subsection{Problem Statement}

Compositional variability in batch minerals is thought to be a significant contributor to lost fiberglass production, as well as lost production in other glass industry sectors. While mining companies provide compositional data on their shipments of batch ingredients, these figures are from only one small sample pulled from the shipment, and may not be representative of the entire shipment. Furthermore, upon delivery to the glass plant silos each shipment is mixed in with remnants from prior shipments that are still in storage. The degree to which these shipments are mixed is unknown. Therefore, for precise knowledge of the minerals entering the furnace, the batch material exiting the silos should be tested. Currently, there is no instrument capable of rapidly measuring mineral compositions in this fashion.

The goal of this project was develop a Laser Induced Breakdown Spectroscopy (LIBS) technology to measure the chemical makeup of glass batch and cullet feedstock in real time and in-site. This device can immediately determine if the process or feedstock is off-spec and can be used in a feedback control loop to correct problems. This work will allow a manufacturer the ability to control the entire process resulting in improvements in quality and productivity, as well as reductions in energy use and emissions.

\subsection{Teaming members}

The following organizations were involved in the work reported here.

- Department of Energy's Industrial Technology Programs

- ERCo - The prime contractor, and owner of the intellectual property.

- PPG - The largest fiberglass manufacturer in the US. PPG hosted the glass batch work.

- Fenton Glass - Assisted in the glass work.

- Oakridge National Laboratory 


\section{Technology Solution}

\subsection{LIBS Description}

ERCo has developed a laser instrument to measure the elemental concentrations of industrial melts, in-situ and in real time. Termed LIBS for Laser Induced Breakdown Spectroscopy, the concept is shown in Figure 1. It is an optical atomic emission technique in which a high energy plasma is formed using a laser pulse. A pulsed laser is repetitively fired through a fiber optic cable, which is placed over the batch. A small amount of melt absorbs the laser light and is rapidly vaporized and ionized. Light from the spark is gathered by another lens and focused on a second fiber optic cable that carries the signal to the spectrometer. The spectrometer resolves the light into different wavelengths and sends the signal to the computer for analysis. The wavelengths observed uniquely identify the elements present ( $\mathrm{Al}, \mathrm{Cu}, \mathrm{Mn}, \mathrm{Si}, \mathrm{Na}, \mathrm{Ca}, \mathrm{Mg}, \mathrm{Ba}, \mathrm{B}, \mathrm{Al}$, $\mathrm{Fe}, \mathrm{Sc}, \mathrm{Mn}, \mathrm{Cr}$ for instance) and the emissions' strength are used to determine the concentration of each element.

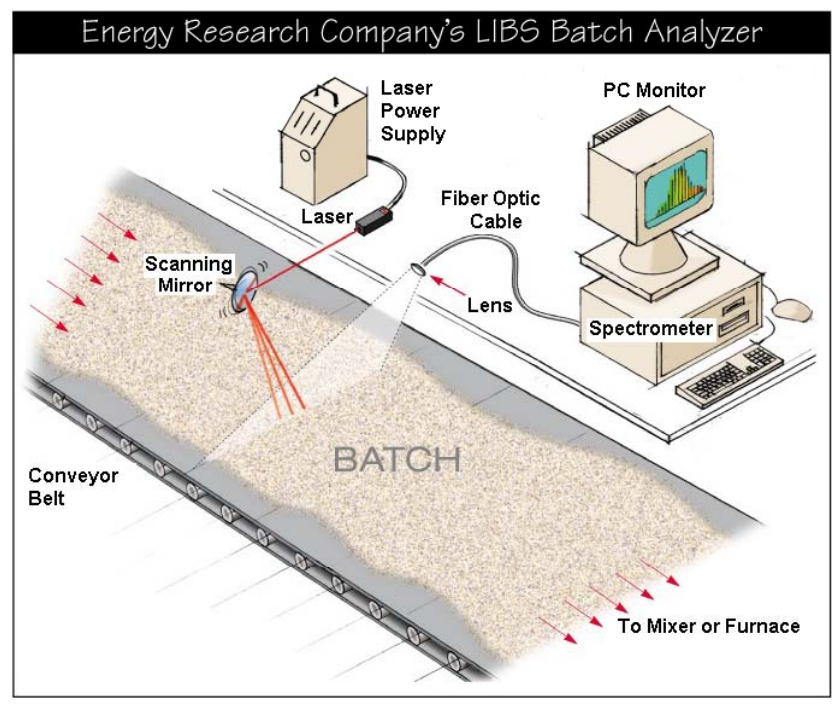

Figure 1 - Schematic of Batch Analyzer

Figure 2 shows a section of typical LIBS spectra taken in ERCo's laboratory from two aluminum alloys, 1100 and 2024, showing spectral lines from a number of minor elements in the alloys. These lines are identified from tables of emission lines for the different elements. To convert LIBS spectra to concentration measurements, the areas under spectral peaks for different elements are measured and correlated to actual concentrations. For instance, the 2024 alloy has about 4 to $5 \%$ copper, while the 1100 alloy has .05 to $0.2 \%$ copper. The peak and area of the copper line is consequently larger for the 2024 than for the 1100. This difference is characteristic of all elements and their relative concentrations and is used by ERCo to quantify absolute concentrations. 
The spark size is about 1 to $2 \mathrm{~mm}$ in diameter. Since the system takes a measurement about once per second and since the probe can be moved vertically and laterally, the measurements will represent the true composition of the melt and will measure spatial as well as temporal variations.

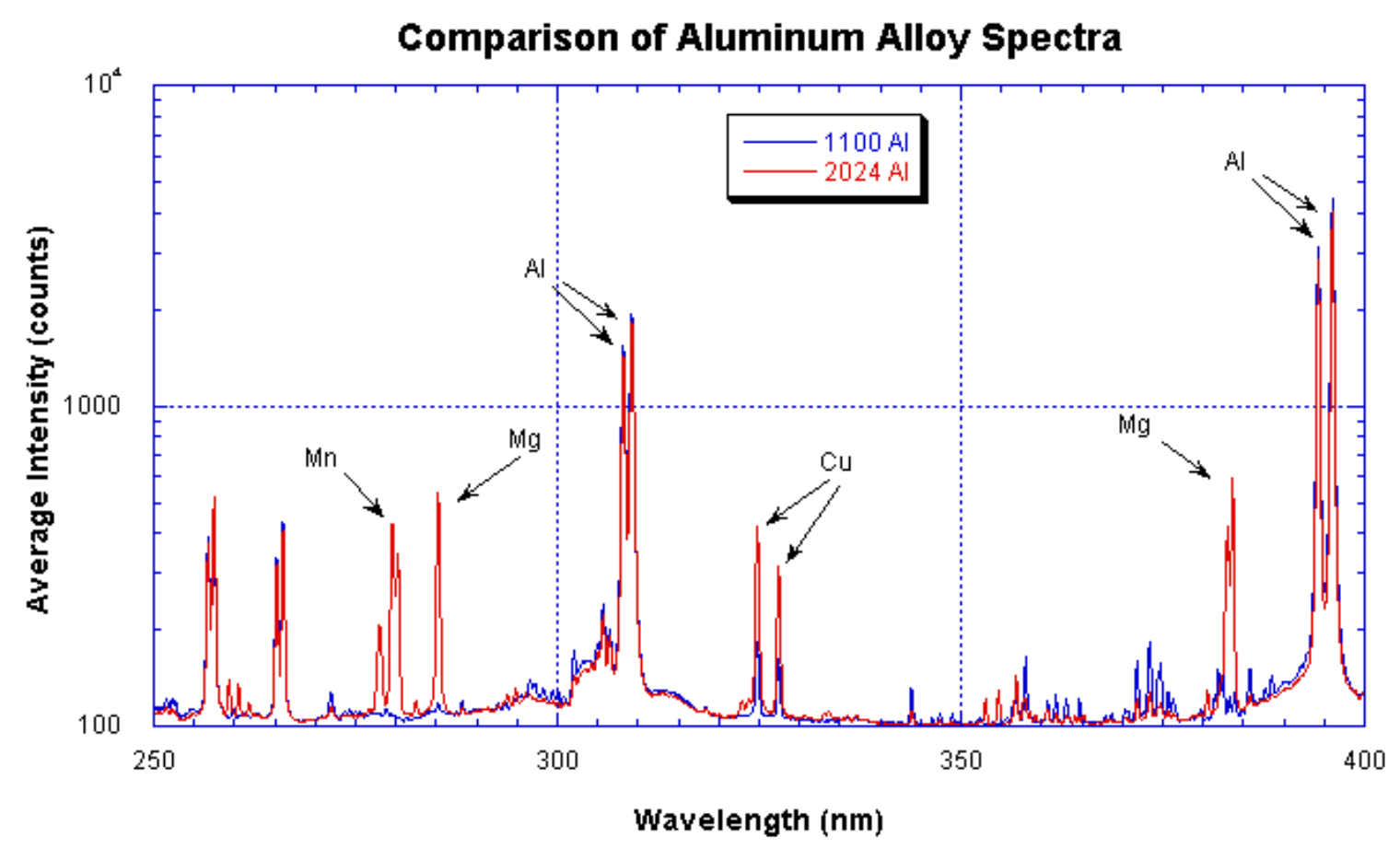

Figure 2 - LIBS Spectra

LIBS has advantages over other measurement techniques because it requires minimal sample preparation, does not require the target to be electrically conductive, can detect both high and low-Z elements (unlike XRF), and can be deployed in difficult-to-reach areas such as beneath the surface of the melt in a glass furnace.

A critical step in the development of practical LIBS systems for analysis of glass batch, cullet, and molten glass was the creation of unique software capable of interpreting the LIBS spectra for the desired application. In batch and molten glass analyses, the goal is to accurately measure the concentrations of all elements present in the sample. ERCo has developed a calibrationless (C-MORE ${ }^{\mathrm{TM}}$ ) method that computes elemental concentrations by modeling the fundamental physics of the LIBS plasma, thereby eliminating the need for system calibration. This is a significant advantage over other analytical techniques that require periodic re-calibration with certified standards of known composition, as well as daily checks for calibration drift. This is particularly important in molten glass because the interaction between the laser and the target material is different for solid and liquid phases. Consequently, molten analytical standards would be needed to calibrate 
and check the system if a calibration method were used; this would be difficult if not impossible to achieve in a practical setting.

In the case of cullet, ERCo's software uses spectral fingerprinting to identify different types of cullet and to differentiate contaminants from similar-colored cullet (clear pyrex from flint glass, for example) that cannot be differentiated by standard optical colorsorters. In this method, LIBS spectra are collected for each type of cullet to be sorted. These spectra are stored in a database of "spectral fingerprints", unique to each sample type (See Figure 1). When sorting, a single LIBS spectrum is collected from each particle in the feed stream. The particle is identified by comparing its fingerprint to those in the database. In addition to requiring only one spark, the algorithm is amenable to highspeed operation on commonly available computer hardware.

\subsection{Technical Breakthroughs}

ERCo has made several technical breakthroughs that now allow the technology to be commercially saleable. See Chapter 5 for a detailed discussion.

- Calibration Free Equipment (C-MORE) - By modeling the plasma, the concentration values can be determined without ever calibrating the instrument. This allows the system to be easy to operate and does not require any operator training.

- Software Development - Along with the C-MORE technology, the LIBS System requires only single button operation, making it easy to operate at a plant.

- Eye Safe - By using a series of safety interlocks, the LIBS system has been certified to be eye safe and no safety training is required.

\subsection{Crosscutting Technology}

The LIBS technology developed by ERCo is a crosscutting technology in that it has a large number of applications. The underlying technology for each of the applications is the same, as described above, with each application dictating somewhat different packaging and ancillary equipment. The applications either developed or under development by ERCo are:

- Molten aluminum (Installed at Aleris)

- Molten glass

- Molten steel (Demonstration to be conducted at Crucible Specialty Metals)

- Glass batch (Installed at PPG)

- Coal for electric utility power plants (Demonstration to be conducted at Brayton Point Power Plant).

- Alloy sorting 


\section{Laboratory Development}

\subsection{Batch}

\subsubsection{Experimental Setup}

Batch samples provided by PPG were tested in ERCo's laboratory. The batch samples were loaded inside a measurement chamber, shown in Figure 3. Infrared laser pulses at $1064 \mathrm{~nm}$ from a pulsed Nd:YAG laser (Ultra CFR, Big Sky Laser Technologies, Inc., Bozeman, MT) were focused on the powdered sample through a lens. Light from the resulting plasma was collected through a small collimating lens and focused into an optical fiber, which directed it into a spectrometer. The sample was mounted to a motorized $\mathrm{X}-\mathrm{Y}$ stage, which was translated between laser shots to ensure that fresh material was sampled each time. A total of 50 laser shots were collected and averaged for each measurement. Samples were prepared by spreading a small amount of powder on the top surface of a piece of double-sided polyethylene tape. The bottom side of the tape was attached firmly to a rigid steel sample holder. The spectrometer, laser power supply, sample chamber, and control computers were mounted inside a movable cabinet as shown in Figure 4.

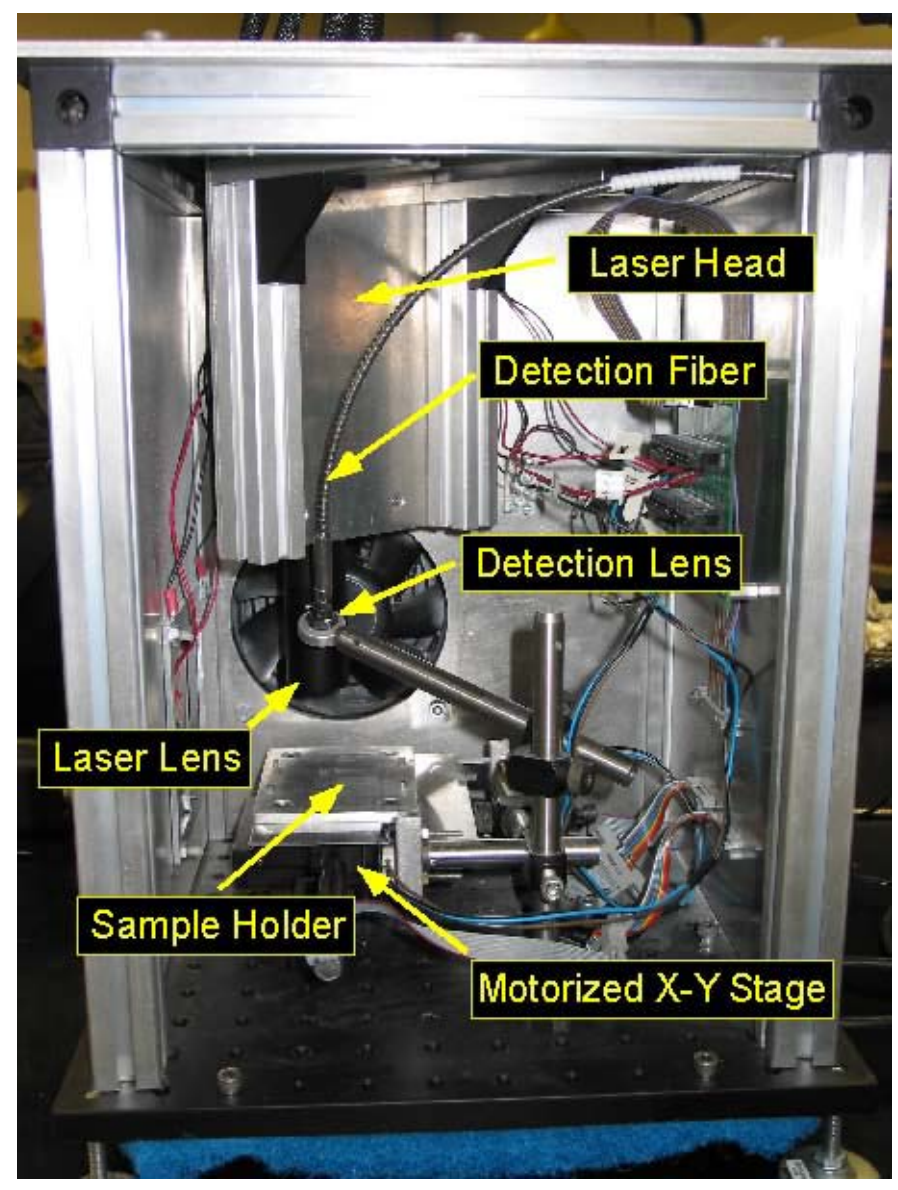

Figure 3 -Photograph of Experimental Setup for Laboratory Ulexite Tests 


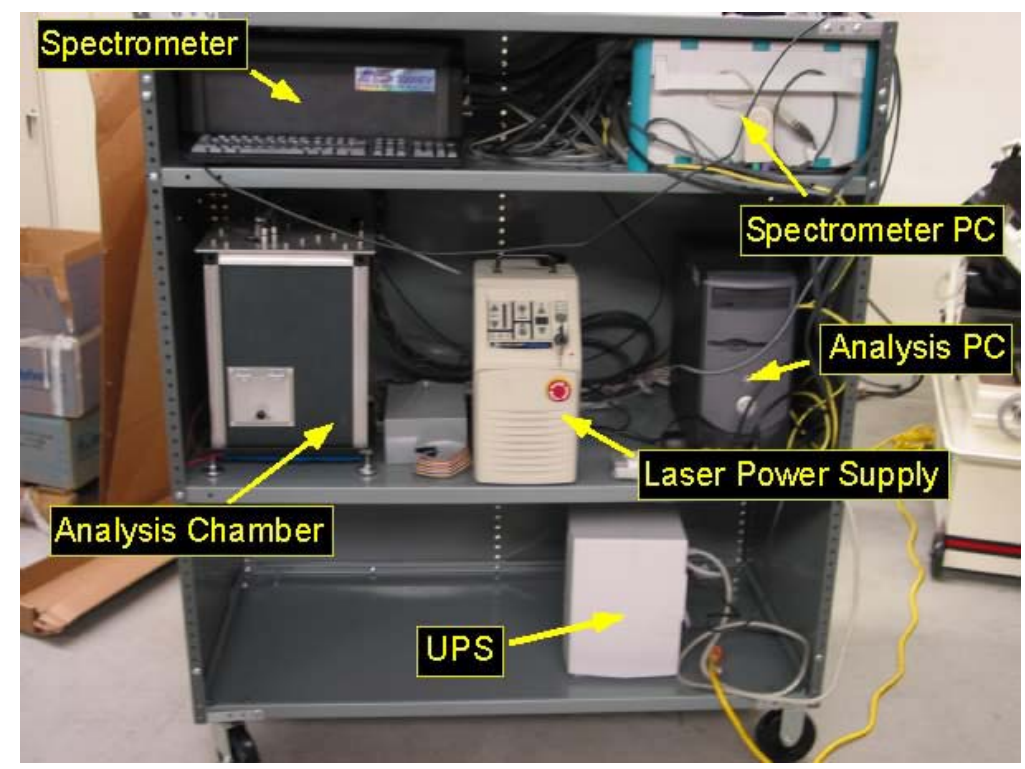

Figure 4 -Cabinet for LIBS Tests on Ulexite

\subsubsection{Laboratory Tests}

Initial laboratory tests were conducted for various raw materials used in making fiberglass. The objectives of these tests were to determine the optimal; laser, optical, and spectrometer parameters for collecting LIBS spectra, and to test the C-MORE ${ }^{\mathrm{TM}}$ algorithm on numerous samples of widely varying composition.

Samples of clay, silica, and limestone, all batch ingredients in fiberglass, were obtained from PPG Fiberglass ${ }^{1}$, along with chemical composition information, and analyzed in our LIBS laboratory. Small amounts of sample were deposited on one surface of doublesided tape and placed at the focus of an f/2 lens. An actively Q-switched Nd:YAG laser operating at its fundamental wavelength $(1064 \mathrm{~nm})$ at $50 \mathrm{~mJ}$ per pulse with a pulse width of 5ns (Ultra CFR, Big Sky Laser, Bozeman MT) was used to generate the plasma. A $5 \mathrm{~mm}$ diameter $\mathrm{f} / 2$ lens coupled to a $600 \mu \mathrm{m}$ UV-grade fused silica fiber was used to collect the plasma light and direct it into the entrance slit of a broadband (200-780nm) spectrometer. (ESA 3000, LLA, Germany). Fifty LIBS spectra were averaged for each measurement and the average spectrum was analyzed using ERCo's C-MORETM method. Five measurements were made for each batch ingredient. .

Because the actual concentrations are proprietary to PPG, the results are given in terms of percent relative error for major constituents and absolute difference between the measured and reported concentrations for minor constituents. The results for all samples tested are given in Tables 1 through 6:

\footnotetext{
${ }^{1}$ Harmarville,PA
} 
Table 1: Results of Clay Analysis as Percent Relative Error (relative) - Major Constituents

\begin{tabular}{|ccccccc|}
\hline Element & Run A & Run B & Run C & Run D & Run E & Average \\
\hline $\mathrm{Al}$ & $0.10 \%$ & $1.38 \%$ & $0.65 \%$ & $1.42 \%$ & $1.93 \%$ & $\mathbf{1 . 1 0 \%}$ \\
\hline $\mathrm{Si}$ & $0.21 \%$ & $2.64 \%$ & $2.64 \%$ & $2.16 \%$ & $2.37 \%$ & $\mathbf{2 . 0 0 \%}$ \\
\hline
\end{tabular}

Table 2: Results of Clay Analysis (Absolute difference in Wt\%) - Minor Constituents

\begin{tabular}{|ccccccc|}
\hline Element & Run A & Run B & Run C & Run D & Run E & Average \\
\hline $\mathrm{Na}$ & 0.03 & 0.03 & 0.03 & 0.03 & 0.03 & $\mathbf{0 . 0 3}$ \\
\hline $\mathrm{Ti}$ & 0.13 & 0.04 & 0.04 & 0.37 & 0.23 & $\mathbf{0 . 1 6}$ \\
\hline $\mathrm{Fe}$ & 0.08 & 0.01 & 0.09 & 0.09 & 0.06 & $\mathbf{0 . 0 7}$ \\
\hline
\end{tabular}

Table 3: Results of Silica Analysis as Percent Error (relative) - Major Constituent

\begin{tabular}{|ccccccc|}
\hline Element & Run A & Run B & Run C & Run D & Run E & Average \\
\hline Si & $0.10 \%$ & $0.20 \%$ & $0.23 \%$ & $0.18 \%$ & $0.18 \%$ & $\mathbf{0 . 1 8 \%}$ \\
\hline
\end{tabular}

Table 4 : Results of Silica Analysis (Absolute difference in Wt\%) - Minor Constituents

\begin{tabular}{|ccccccc|}
\hline Element & Run A & Run B & Run C & Run D & Run E & Average \\
\hline $\mathrm{Al}$ & 0.05 & 0.02 & 0.04 & 0.01 & 0.01 & $\mathbf{0 . 0 3}$ \\
\hline $\mathrm{Ti}$ & 0.01 & 0.01 & 0.01 & 0.00 & 0.00 & $\mathbf{0 . 0 1}$ \\
\hline $\mathrm{Fe}$ & 0.01 & 0.02 & 0.02 & 0.00 & 0.00 & $\mathbf{0 . 0 1}$ \\
\hline
\end{tabular}

Table 5: Results of Limestone Analysis as Percent Error (relative) - Major Constituents

\begin{tabular}{|ccccccc|}
\hline Element & Run A & Run B & Run C & Run D & Run E & Average \\
\hline C & $1.28 \%$ & $0.62 \%$ & $1.54 \%$ & $1.59 \%$ & $0.09 \%$ & $\mathbf{1 . 0 2 \%}$ \\
\hline Ca & $0.26 \%$ & $0.09 \%$ & $0.57 \%$ & $0.41 \%$ & $0.18 \%$ & $\mathbf{0 . 3 0 \%}$ \\
\hline
\end{tabular}

Table 6: Results of Limestone Analysis (Absolute difference in Wt\%) - Minor Constituents

\begin{tabular}{|ccccccc|}
\hline Element & Run A & Run B & Run C & Run D & Run E & Average \\
\hline $\mathrm{Mg}$ & 0.00 & 0.00 & 0.01 & 0.01 & 0.00 & $\mathbf{0 . 0 0}$ \\
\hline $\mathrm{Al}$ & 0.01 & 0.01 & 0.00 & 0.01 & 0.01 & $\mathbf{0 . 0 1}$ \\
\hline $\mathrm{Si}$ & 0.08 & 0.07 & 0.10 & 0.10 & 0.13 & $\mathbf{0 . 1 0}$ \\
\hline $\mathrm{Fe}$ & 0.00 & 0.00 & 0.01 & 0.04 & 0.02 & $\mathbf{0 . 0 1}$ \\
\hline
\end{tabular}

The relative errors for all major constituents were within 3\% for all measurements. This is well within the reported uncertainties in the certified standards used to calibrate laboratory instruments. 


\subsection{Cullet Sorting}

When recycling glass cullet, it is necessary to sort the cullet particles by color (typically clear flint, amber, and green glass for containers) and to eliminate contaminants. Identification of cullet pieces must occur rapidly as the cullet is moving on a conveyor. An initial set of laboratory tests was conducted using cullet obtained from a variety of independent sources as well as a number of typical contaminants. The objective of these tests was to determine the ability of LIBS to categorize materials at speeds similar to those expected in a commercial setting.

Figure 5 shows a schematic drawing of ERCo's laboratory LIBS apparatus when configured to identify cullet on a rotating turntable. Rotating the cullet beneath the laser pulses allows us to simulate cullet flowing in a sorting machine past the LIBS sensor at high speeds. The laser fires a pulse of UV laser light towards the piece of cullet where it is focused to create a LIBS spark. The light from the spark is collected by the focusing lenses and sent to the spectrometer system via a fiber optic cable. The computer then analyzes the results and determines the identity of the sparked cullet. During actual experiments, the turntable is filled with cullet.

Cullet sorting tests were conducted on 25 glass samples of varying colors, including 6 contaminants. The cullet samples were placed on a turntable and rotated beneath the laser lens in order to simulate cullet flowing in a commercial sorter. Rotation rates corresponding to cullet velocities in a commercial sorter were used. A photograph of a LIBS spark on cullet rotating on the turntable is seen in Figure 6. A frequency-doubled, Q-Switched Nd:YAG laser with a pulse energy of approximately $150 \mathrm{~mJ}$ at $532 \mathrm{~nm}$ and operating at $20 \mathrm{~Hz}$ was used for excitation, and a $300 \mathrm{~mm}$ Czerny-Turner spectrograph, coupled to a gated intensified CCD camera was used for detection.

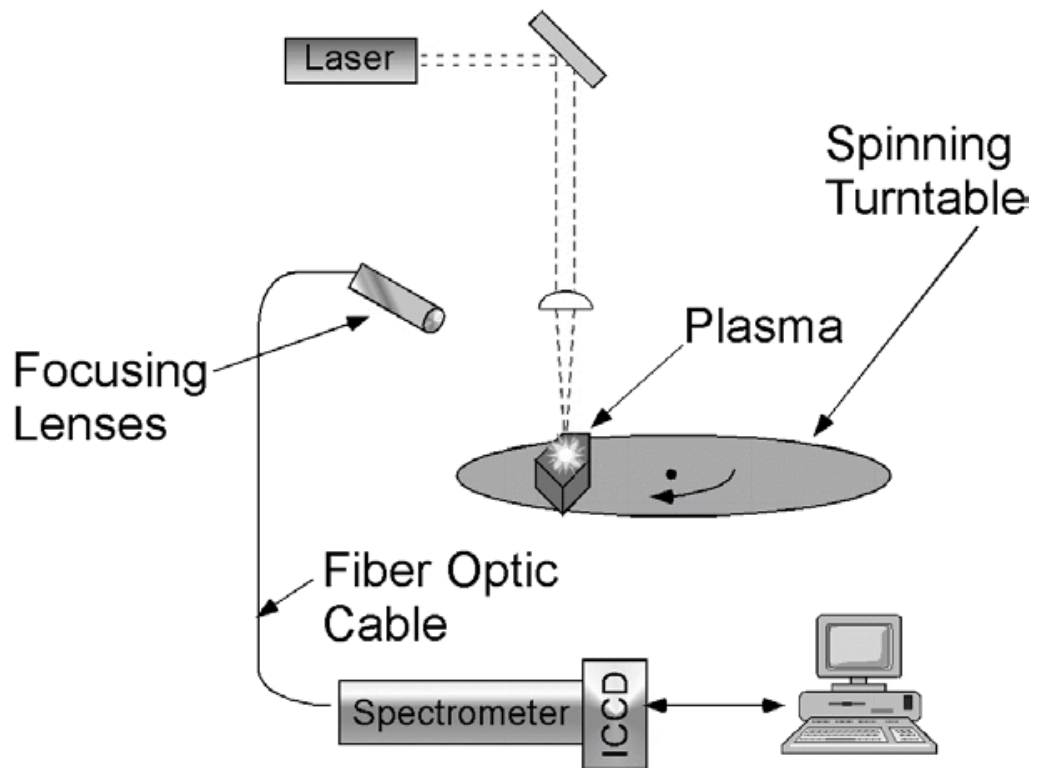

Figure 5-Cullet Sorting Schematic 

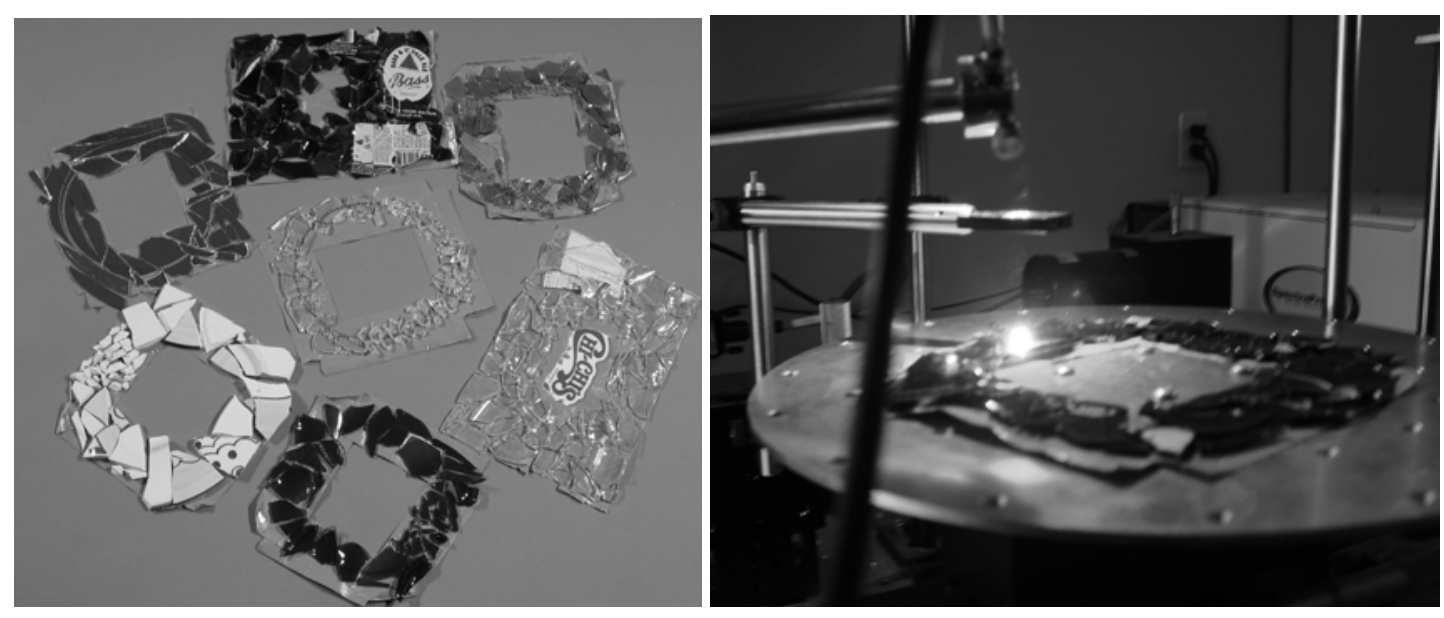

Figure 6 -Samples of Cullet and Contaminants (Left) and a Photograph of a LIBS Spark on Rotating Cullet (Right)

12,000 spectra were collected and sorted using ERCo's LIBS software. The software was configured to use only certain (small) segments of the LIBS spectrum for analysis, simulating an industrial system, which would use fast, single channel silicon detectors and band-pass filters for detection in place of the much slower spectrometer. LIBS spectra from flint, green, and amber cullet along with contaminants ranging from clear pyrex, to ceramic dishware, to silvered glass were initially collected and used to form the database of known spectral "fingerprints". Single spectra from the unknown samples (rotating on the turntable) were collected and compared to the known data.

The results are shown in Table 1 below:

Table 1 - Summary of Cullet Sorting Test with Silicon Detector Simulation

\begin{tabular}{|ll|}
\hline Color / Contaminant & \% Correct Identification \\
\hline Flint & 97.5 \\
\hline Green & 95.3 \\
\hline Amber & 90.8 \\
\hline Contaminants & 98.5 \\
\hline
\end{tabular}

These results, while not yet at a level suitable for industrial applications are nonetheless encouraging, considering the challenges introduced by limiting the information available to the sorting algorithm. In addition, some of the false identifications may have been caused by laser shots occurring at a junction between samples, or on a section of cullet contaminated by dirt, paint, or label materials. Such errors can be reduced by repeatedly 
firing the laser at a single location prior to making a measurement. These "cleaning shots" serve to remove surface contaminants so that an accurate reading of the glass underneath can be made. A material tracking system can be used to ensure that each laser shot is directed at a suitable target and not at the "dead space" between samples.

\subsection{Molten Glass Sensor}

ERCo is currently developing a sensor that will be able to continuously measure the elemental composition of molten glass at any depth and location within a glass furnace. A conceptual drawing of the design is shown in Figure 17. The molten glass sensor employs the same LIBS technology described above, but in this case both the laser and the return signal are delivered via fiber-optic cables. This is important because it allows the expensive equipment (spectrometer and laser) to be located in an environmentally controlled cabinet, away from the harsh furnace environment.

The optics for focusing the laser and collecting the plasma light are located in an optics tube, which is protected by a water-cooled jacket inside of a protective sheath, which provides structural rigidity for the fragile fibers and optical components as well as protection from chemical and thermal attack.

An inert gas is introduced at the end of the probe that is inserted into the glass melt. This serves both to keep molten glass from flowing into the probe and damaging the optics and to form an aerodynamic window between the probe end and the melt. The location of this window can be adjusted such that it always remains at the focal point of the laser, providing a stable surface from which to collect measurements. A sensor similar in design has been developed by ERCo for molten aluminum and is currently operating in an industrial plant.

A preliminary test was conducted in ERCo's laboratory in which a small quantity of glass was melted in a laboratory furnace. The crucible of molten glass was then removed from the furnace, and placed under the laser-focusing lens for LIBS analysis of the molten surface. Samples of the glass before and after melting were sent to an independent laboratory for chemical analysis. The results are compared to ERCo's C-MORE ${ }^{\mathrm{TM}}$ analysis of the LIBS spectra in Table 2.

The C-MORE ${ }^{\mathrm{TM}}$ results fell within the range of the certified measurements for all but a few elements. The difference between the LIBS and certified measurements for $\mathrm{Mg}$ and Ba can potentially be attributed to the fact that the LIBS measurements were restricted to the surface of the molten glass in air. We have observed similar surface effects with these elements in molten metals, and anticipate that the discrepancies will be eliminated when measurements are made beneath the glass surface in an inert environment. 
Table 2 - LIBS Results on Molten Glass

\begin{tabular}{|l|l|l|l|l|l|}
\hline Element & $\begin{array}{l}\text { Lab Analysis } \\
\text { Before Melting }\end{array}$ & $\begin{array}{l}\text { Lab Analysis } \\
\text { After Melting }\end{array}$ & LIBS Analysis & Result & $\begin{array}{l}\text { Outside } \\
\text { Range } \\
\text { Range }\end{array}$ \\
\hline $\mathrm{Si}$ & 62.96 & 61.51 & 61.01 & Good & 0.81 \\
\hline $\mathrm{Na}$ & 29.67 & 20.72 & 24.9 & Good & \\
\hline $\mathrm{Ca}$ & 5.36 & 3.46 & 4.8 & Good & \\
\hline $\mathrm{Mg}$ & 2.71 & 2.42 & 2.85 & Out & 5.2 \\
\hline $\mathrm{Ba}$ & 4.66 & 0 & 4.79 & Out & 2.8 \\
\hline $\mathrm{Fe}$ & 0.04 & 0.02 & 0.02 & Good & \\
\hline $\mathrm{Sr}$ & 0.04 & 0 & 0.03 & Good & \\
\hline $\mathrm{Mn}$ & 0.1 & 0 & 0.08 & Good & \\
\hline
\end{tabular}




\section{Glass Industry Installation}

\subsection{Introduction}

Based on the success of ERCo's laboratory batch testing, a full-scale LIBS unit was installed at PPG's plant in Chester, SC.

\subsection{Analyzer Components}

ERCo's batch analyzer system components are shown in Figure 7. The analyzer is run by ERCo's LIBS software running on the Windows PC shown in the figure. The sensor hardware requires little maintenance and runs off an ordinary $110 \mathrm{~V}$ electrical outlet.

A close up photograph of the sample chamber is shown in Figure 8. The procedure for analyzing a sample involves placing a few grams of powdered batch material in a custom holder which is then placed inside the chamber door, as seen in Figure 9. The sealed chamber prevents the laser light from escaping into the room, so laser safety training and eyewear are not necessary. The door is interlocked so that the laser will not fire with the door open. Inside the chamber are all the optics and mechanical hardware necessary to perform the LIBS measurements.

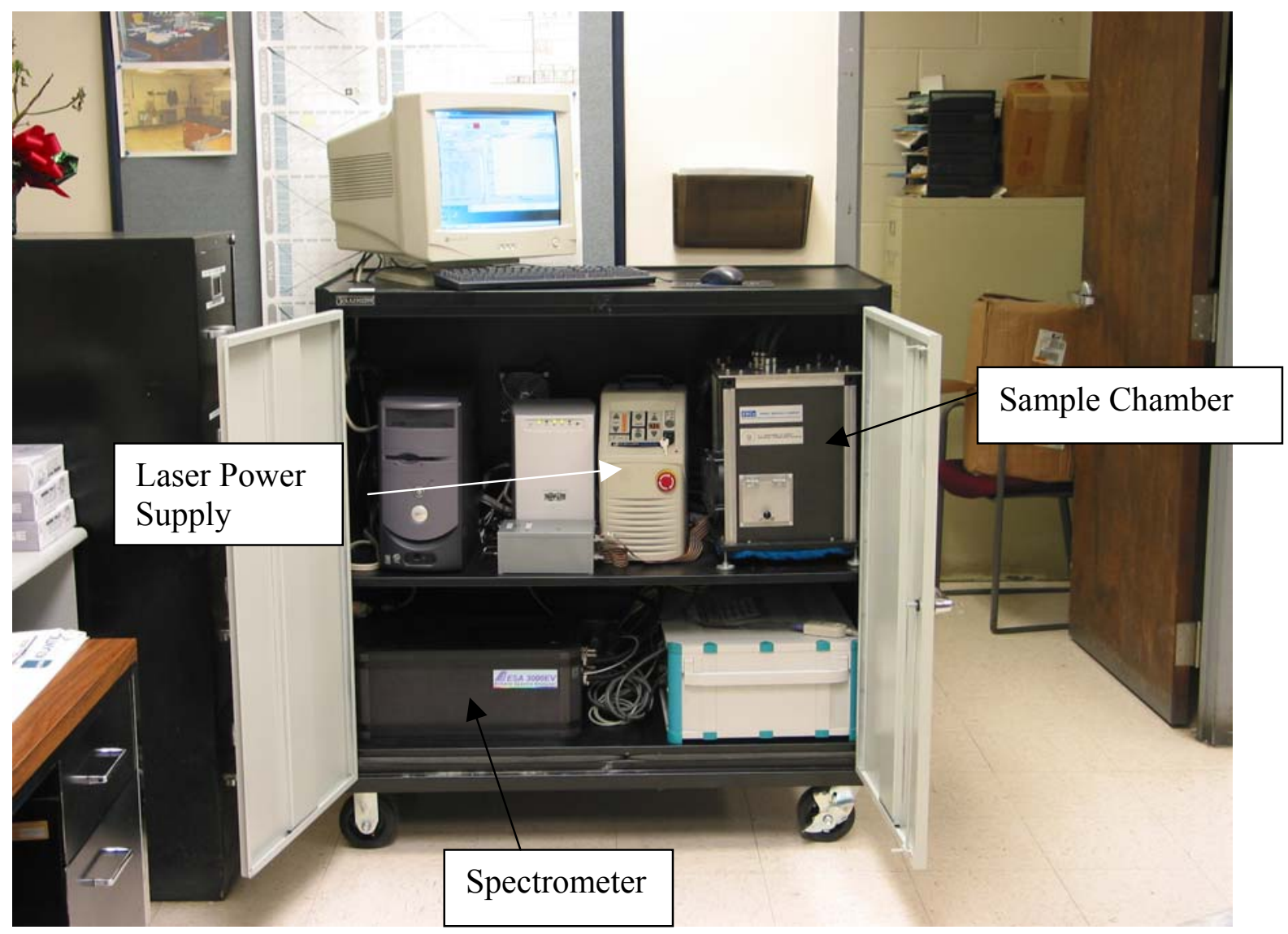

Figure 7 - Photograph of ERCo Batch Analyzer Equipment in PPG Chester Plant 


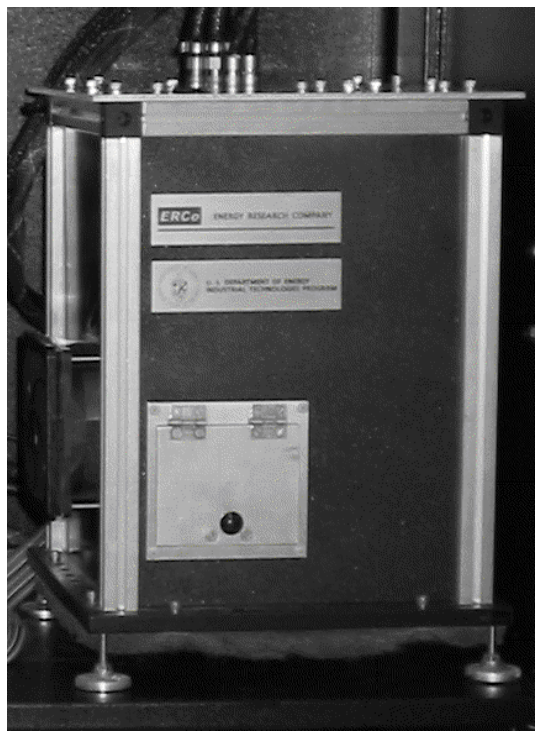

Figure 8 - Close up of Batch Sample Chamber
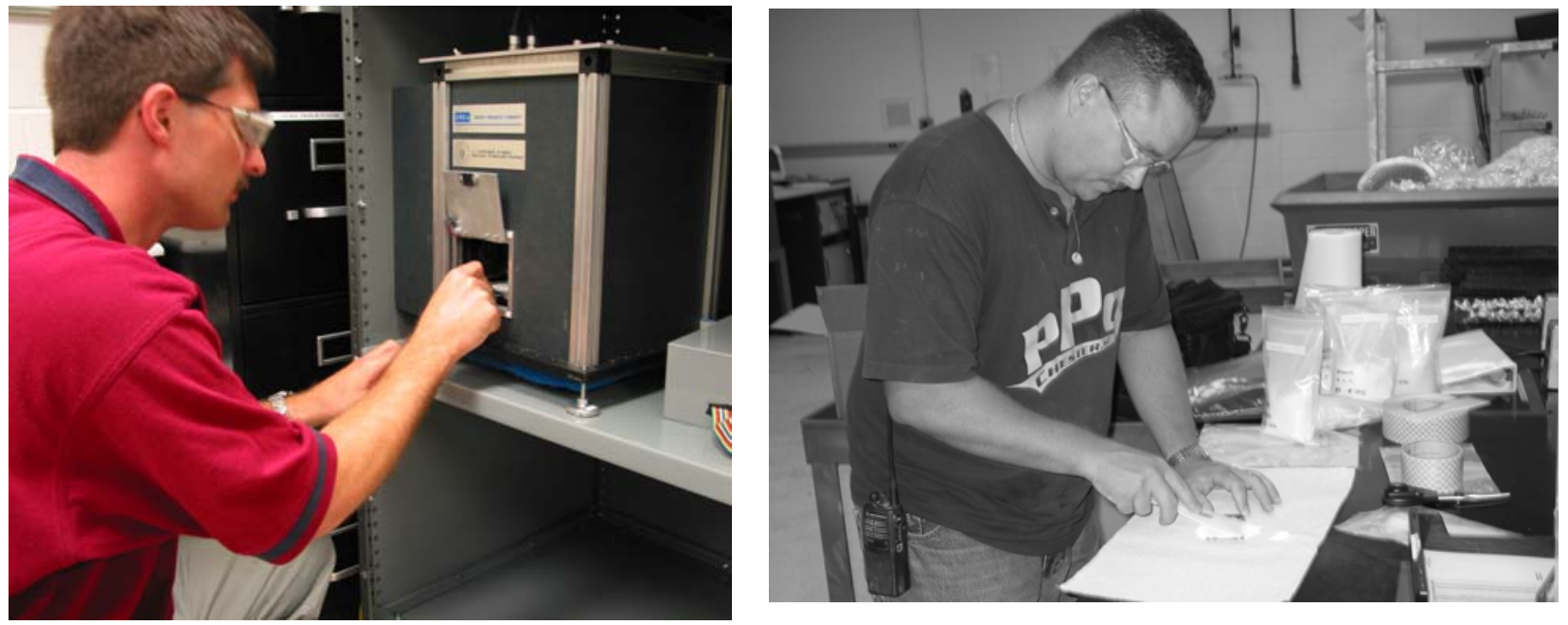

Figure 9 - PPG Production Manager Kevin Streicher Placing a Sample into the Chamber for Analysis (Left) and Batch House Supervisor Phil Gibson Prepares a Ulexite Sample for Analysis (Right)

\subsection{User Interface}

The analyzer is controlled from ERCo's LIBS software package, a "point and click" Windows program, operating on a PC, shown in Figure 10. This software package was instrumental in bringing LIBS technology out of the laboratory and into the plant 
environment. Our goal in developing this software was to enable non-specialist plant personnel to use the analyzer on a regular basis. We achieved this goal as PPG found the software package easy to use and that the results were provided in an easy to understand format.

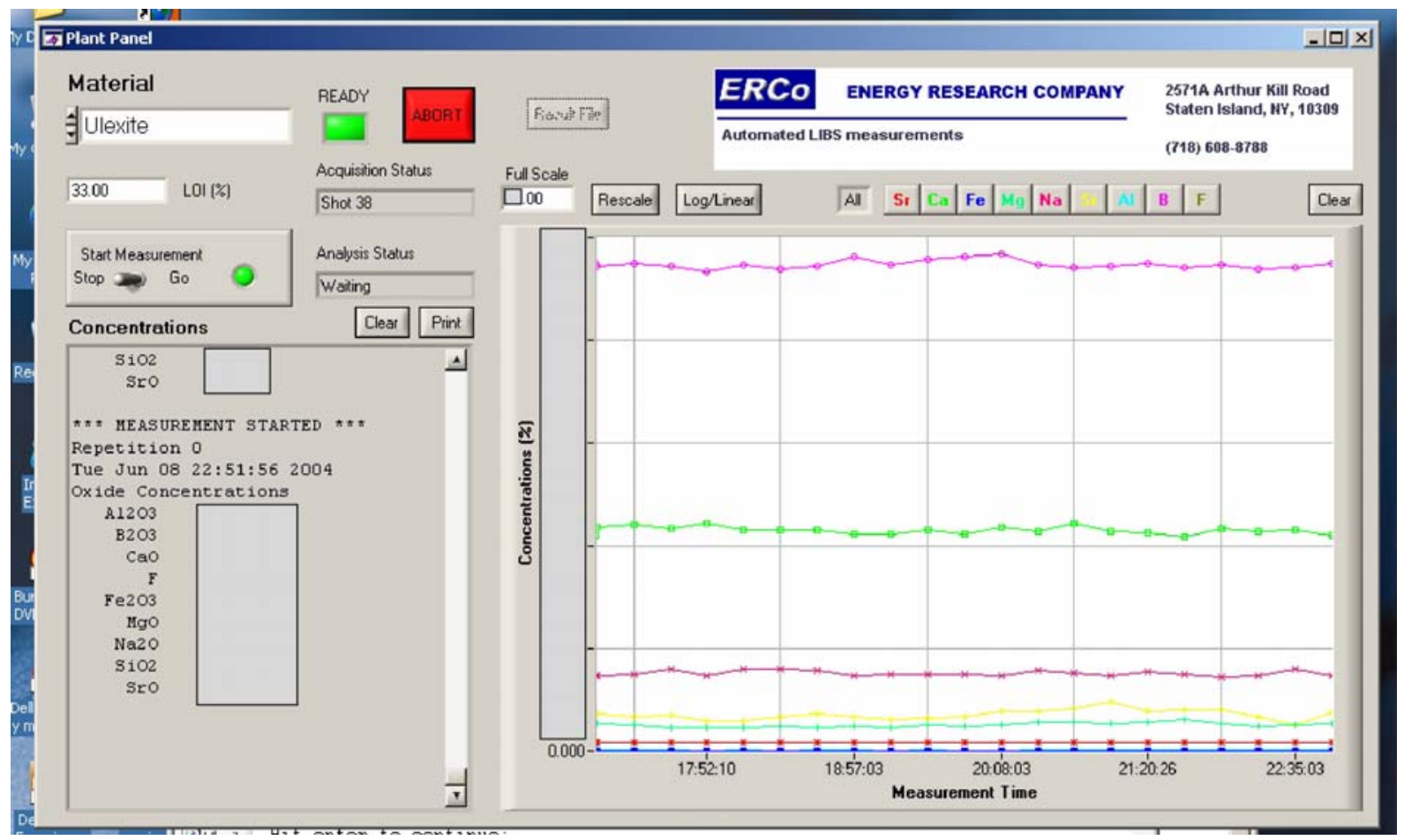

Figure 10 - ERCo's LIBS Software Control Panel

In order to operate the analyzer, the user selects the mineral being analyzed from the drop down menu in the upper left hand corner (ulexite is selected in the figure). Below this menu and the LOI input box ${ }^{2}$ is a toggle switch. By clicking on the toggle switch, it moves from "Stop" to "Go" and the measurement is initiated. The laser is turned on and operated automatically, as is the spectrometer and all the other necessary hardware components, so that no further operator actions are necessary.

In the event that the analysis must be stopped for any reason, the red "Abort" button is provided on the screen. Additionally, if the door on the sample chamber is opened during an analysis, the laser is turned off and the analysis is immediately aborted.

After the data is collected and analyzed, the results are presented on the screen in the text window on the lower left and in the strip chart display on the right (all concentrations are blocked out as they are proprietary PPG data). In addition, the compositional data is

\footnotetext{
${ }^{2}$ The LOI value text box is a placeholder for future software upgrades. It is not used in the current version of the software.
} 
saved in a text file that can readily be imported to any data analysis package or spreadsheet such as Excel.

The data in the strip chart can be viewed all at once, as shown in the figure, or data from one element at a time can be displayed by clicking on the element buttons immediately above the strip chart. Controls are provided for rescaling the y-axis and for switching between a linear and a logarithmic scale. In the single element views, two visible markers can be set to easily see if the data falls within a desired range.

\subsection{Results}

Powdered ulexite samples that were pulled from shipments to PPG over the course of the prior year were used in this test. Each sample was tested five times with the results shown in the figures below for each element. In each figure the blue diamonds are the data provided by the mining company and the purple squares are the LIBS analyzer results.

In each figure caption the average relative difference between the mining company results and the LIBS analysis +/- one standard deviation is given. The actual concentrations are proprietary PPG data, and are therefore blocked out.

The major constituents of ulexite are boron, calcium, and sodium. The first three graphs, Figure 11, Figure 12, and Figure 13, demonstrate the accuracy of the LIBS analyzer for these large percentage constituents. The average difference for between the supplier's data and the LIBS measurements was no greater than $2.75 \%$.

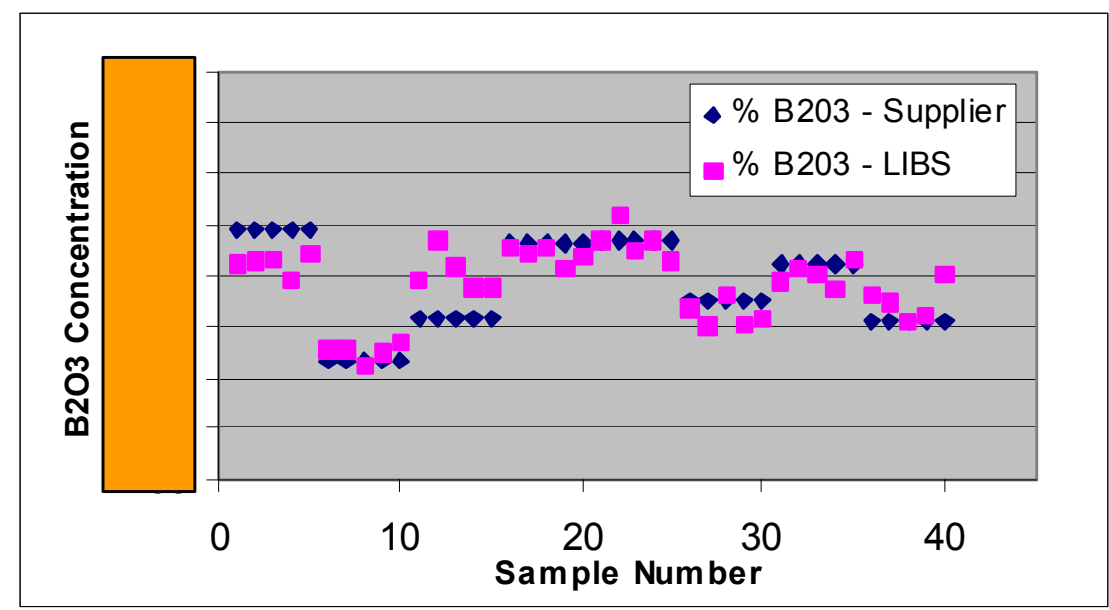

Figure 11 - Boron Average Difference: 0.54\% +/- 0.43\% 


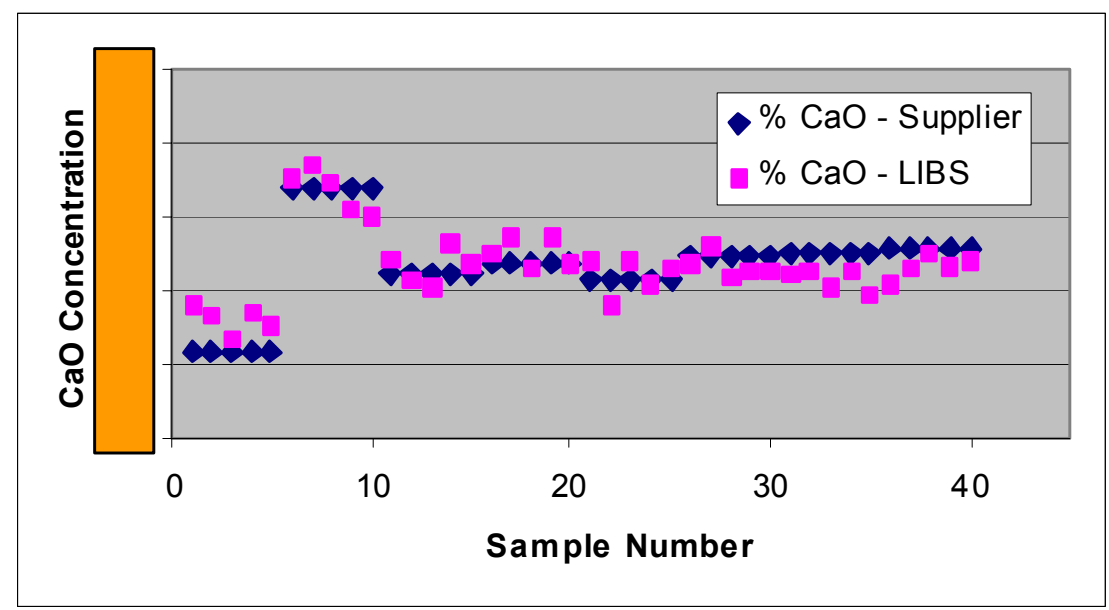

Figure 12 - Calcium Average Difference: 1.51\% +/- 0.94\%

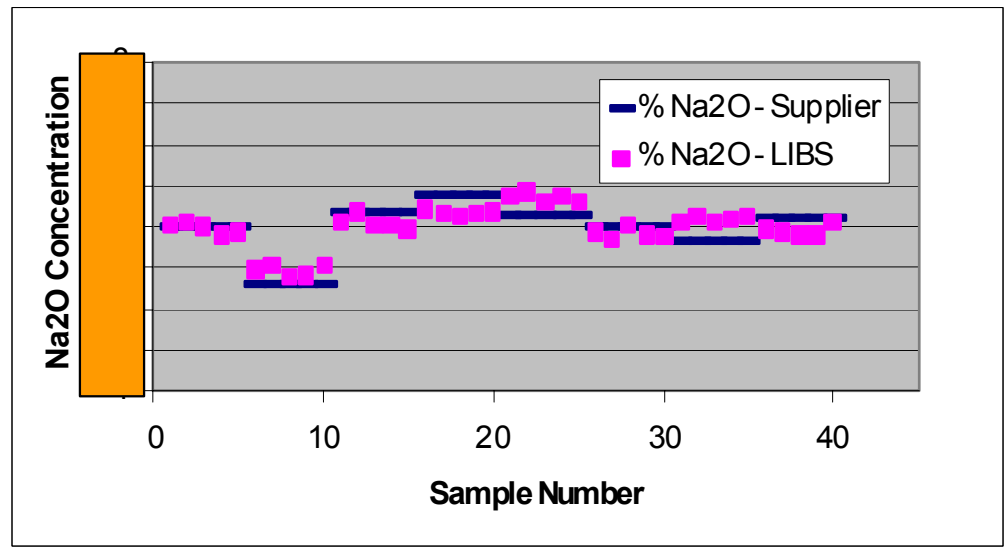

Figure 13 - Sodium Average Difference: $2.75 \%+/-1.54 \%$

Silicon and magnesium are present in much lower concentrations. As in the case of the major constituents, the LIBS analyzer closely tracked the reported data for these elements, shown in Figure 14 and Figure 15. The average difference for these minor elements was no greater than $5 \%$.

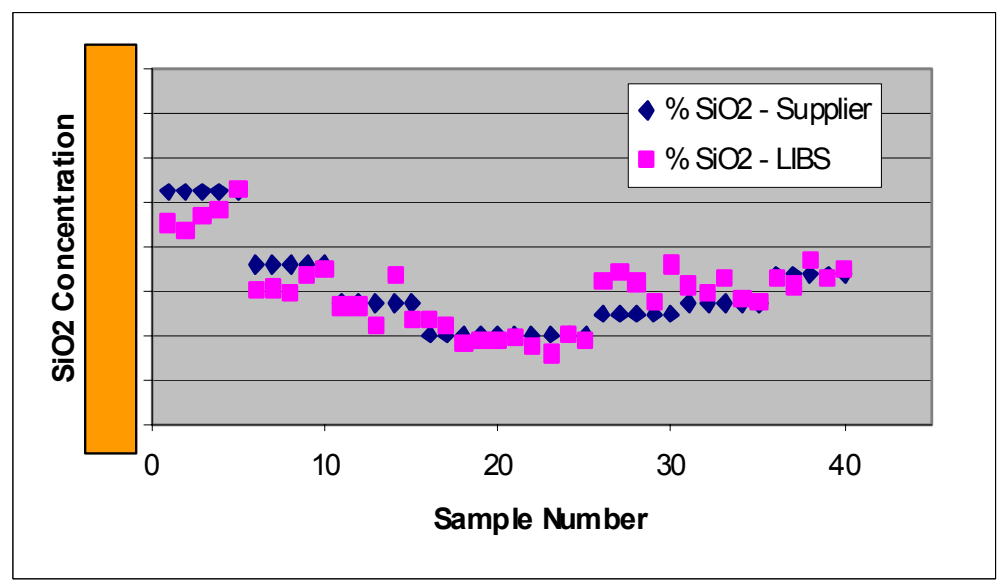

Figure 14 - Silicon Average Difference: $4.98 \%+/-4.02 \%$ 


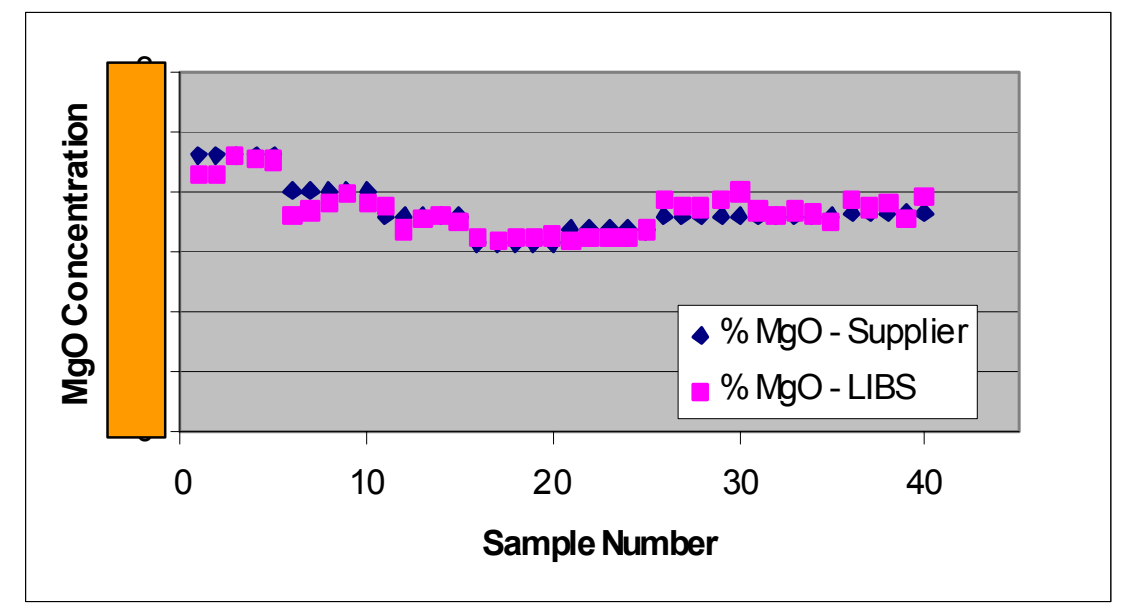

Figure 15 - Magnesium Average Difference: 4.06\% +/- 2.72\%

The last three elements, shown in Figure 16, Figure 17, and Figure 18, are all present in trace quantities. Even at these much lower concentrations, the LIBS analyzer was able to match the mining company data as well. Since the concentration percentages for these elements are so small, the absolute differences between the mining company values and the LIBS analyzer values are relevant, more so than the relative values. Therefore, the percentage difference is reported as absolute percent for these elements, and was no greater than $0.026 \%$.

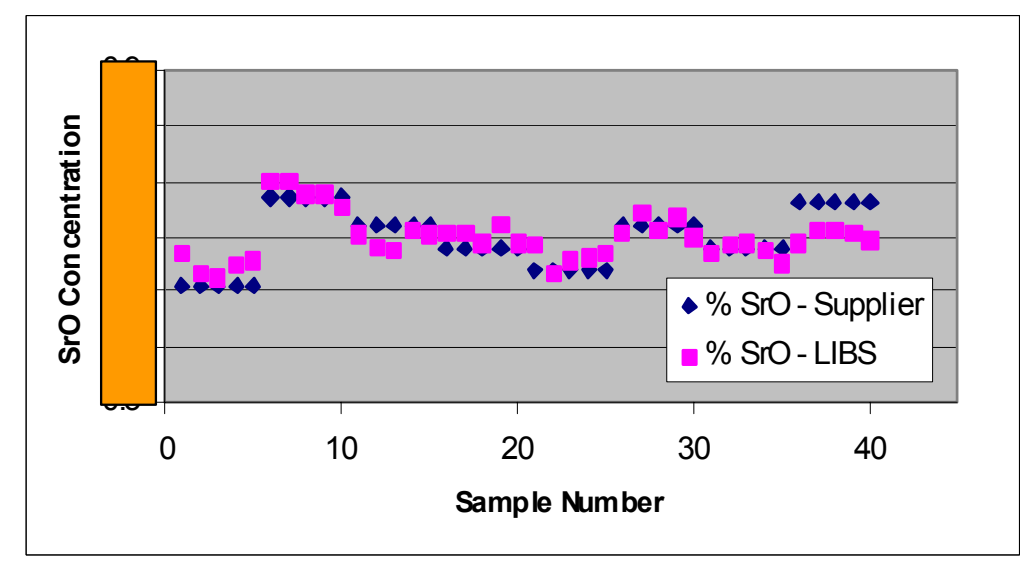

Figure 16 - Strontium Average Difference: 0.026\% +/- 0.018\% 


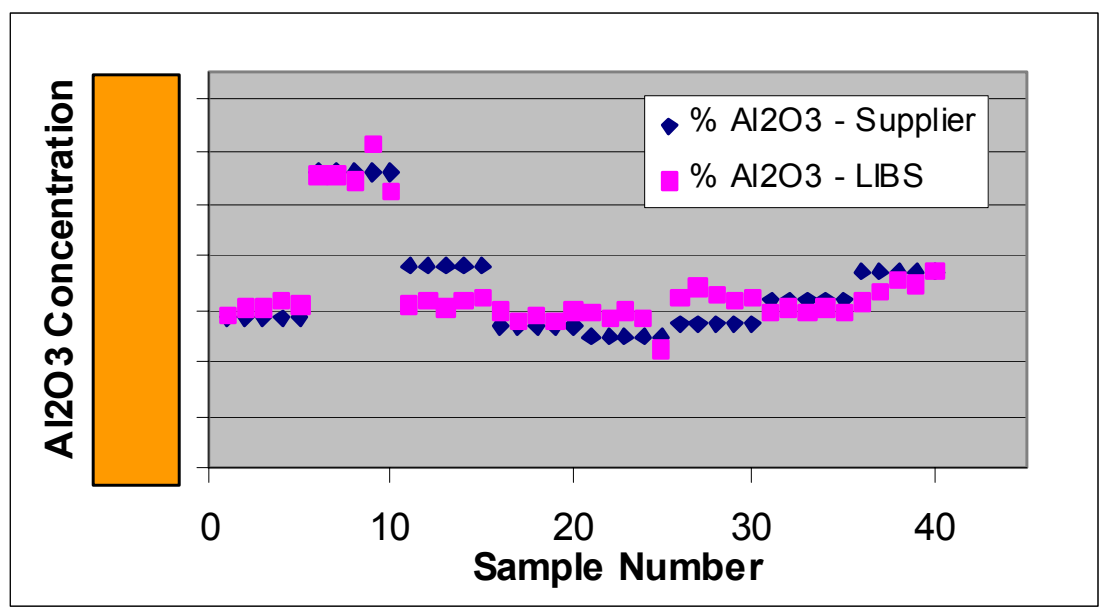

Figure 17 - Aluminum Average Difference: 0.007\% +/- 0.004\%

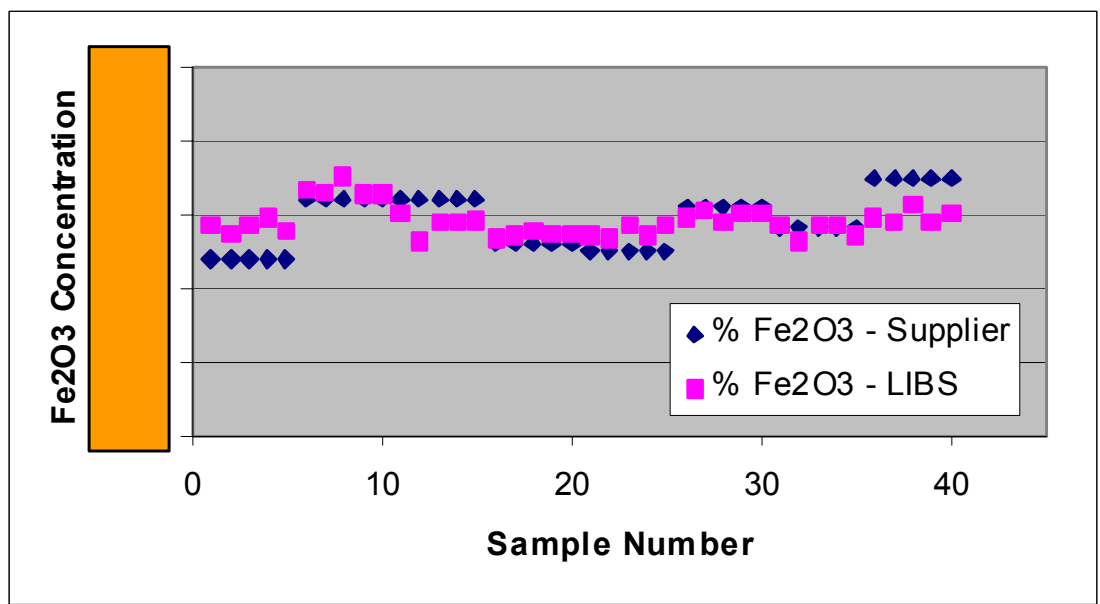

Figure 18 - Iron Average Difference: $0.003 \%$ +/- $0.002 \%$

Following these tests, PPG provided two new ulexite samples without providing the elemental concentrations to ERCo. The mining company only provided boron concentrations for these samples, so this blind test was limited to only measuring boron. The results of the test, in which each sample was tested twice, are shown in Table 3 below. The measured difference was no greater than $0.3 \%$

Table 3 - Results Summary from Blind Tests

\begin{tabular}{|c|c|}
\hline Sample & Boron Concentration Difference \\
\hline A & $0.00 \%$ \\
\hline A & $0.03 \%$ \\
\hline B & $0.24 \%$ \\
\hline B & $0.30 \%$ \\
\hline
\end{tabular}

In addition to the low percentage differences, within each sample the repeatability was high. 


\subsection{Conclusion}

PPG found these results to be highly satisfactory. Across all the elements, from the major constituents down to the trace elements, the LIBS analyzer results tracked the mining company results sufficiently closely for using the LIBS instrument in plant production.

Minerals have a natural variability, therefore perfect correlation between the mining company results and the LIBS results should not be expected. The mining company pulled one sample from a multi-ton shipment while we used a different sample pulled from the shipment for the LIBS tests. The accuracy and precision of the LIBS batch analyzer results should be viewed in light of this fact.

The LIBS system is permanently installed at PPG and is routinely used by PPG personnel. 


\section{Key Advances}

\subsection{Calibration Free Technique}

Any LIBS method critically depends on converting the spectral data to concentration values. All current methods rely on the use of calibration curves. In this method, samples with known elemental concentrations are processed and a linear relationship is produced between the concentration and the spectral signal. However, the results from the calibration samples and the actual materials to be measured can differ significantly because of variability in the laser-material interaction due to, for example, changes in surface texture from sample to sample or the laser power diminishing slightly as the laser ages $^{3}$. The end result is a change in the signal-to-concentration correlation because the amount of material vaporized by the laser pulses has likely changed, as well as the temperature and other properties of the vaporized material. The effect is most pronounced when different types of materials are compared, and it becomes impossible to use solid samples as calibration standards for molten materials.

Hence, for molten glass or aluminum measurements, calibration curves would need to be developed using molten calibration standards. This would be difficult to do routinely in an industrial plant environment, in which a limited number of trained personnel are available. In addition, it would be quite expensive to obtain certified samples each time a calibration was needed. Once melted, the standards could not be reused since some elements would volatilize, thus invalidating the concentration specification.

At ERCo, we have overcome these problems by modeling the plasma. Our work follows that of CNR's laboratory in Pisa, Italy ${ }^{4}$. Termed C-MORE (calibrationless) the plasma is modeled as follows. A LIBS plasma contains neutral and ionized atoms from each element present. Measuring the concentration of an element therefore requires measuring the concentration of each state of that element. At plasma temperatures typical of LIBS experiments, for these states, or species, only two are present of each element: the neutral state and the singly ionized state For example, the total concentration of calcium in a sample would be the sum of the concentrations of the $\mathrm{Ca}$ I and $\mathrm{Ca}$ II atoms (where I designates neutral and II the singly ionized lines).

When the LIBS plasma is in a state of local thermodynamic equilibrium (LTE), the integrated intensity $I$ of any emission line from a species $S$ present at a concentration $C_{S}$ can be written as (reference 4):

$\overline{I_{\lambda}^{k i}}=F C_{S} A_{k i} \frac{g_{k} e^{-\left(E_{k} / k_{B} T\right)}}{U_{S}(T)}$,

where the line at wavelength $\lambda$ is a result of an electronic transition from energy state $k$ to energy state $i$. $A_{k i}$ is the transition probability, $g_{k}$ is the degeneracy of the state, $E_{k}$ is the

\footnotetext{
${ }^{3}$ Chaleard, C. et al, "Correction of Matrix Effects in Quantitative Elemental Analysis with Laser Ablation Optical Emission Spectrometry", Journal of App. Atomic Spectrometry, Feb. 1997, vol. 12 (183-188)

${ }^{4}$ Ciucci, A. et al, "New Procedure for Quantitative Elemental Analysis by Laser-Induced Plasma Spectroscopy”, Applied Spectroscopy, 53, 8, 1999, pp.960-964
} 
value of the upper energy state, $k_{B}$ is the Boltzmann constant, $T$ is the plasma temperature, and $U_{S}(T)$ is the partition function for the species at the plasma temperature.

$F$ is an experimental factor which includes fluctuations in the plasma due to varying laser power, degree of focus, and surface character. The intensity $I$ must be normalized by the spectral response of the light detection system for $F$ to be independent of wavelength.

As shown in the test results in previous sections, the C-MORE method works well and allows the LIBS system to be operated with no training.

\subsection{Eye Safe}

The LIBS System has been designed to be eye safe and complies with 21 CFR 1040.10 and 1040.11 except for deviations pursuant to Laser Notice No. 50, dated July 26, 2001. Hence, no safety training is required and no special safety precautions need to be taken.

\subsection{Software Development}

ERCo has developed software that incorporates the C-MORE technology and the eye safe system. No other actions are required.

\subsection{No Operator Training Required}

From the above, no operator training is required. The operator simply presses a button and immediately data on the process is provided.

\subsection{Worldwide Patent}

A world wide patent has been issued - Patent number US 6,784,429 B2. In addition, a considerable amount of know-how and trade secrets have been developed. This includes ERCo's C-MORE techniques. 


\section{Energy Savings}

\subsection{Introduction}

For the glass industry, 350 trillion Btu were expended in 1995 with pack to melt rates of 85 to $93 \%$ (i.e. $7 \%$ to $15 \%$ of the glass melt is scrapped). Hence, 24.6 to 52.5 trillion Btu are wasted each year. Rejected products result from variations in glass melt composition and non-repeatability in the mechanics of forming. Further, product rejections occur after all the energy intensive operations have been completed. With the proposed technology, it is estimated that packs can go up to $98 \%$, saving 17 to 45 trillion Btu per year. 


\section{Technology Transfer}

Two LIBS Systems are operating commercially.

The following papers have been published:

1. De Saro, "LIBS Applications in the Aluminum, Glass, and Steel Industries", $3^{\text {rd }}$ International Conference LIBS 2004, Laser Induced Plasma Spectroscopy Applications, Malaga, Spain, 28 Septemberto 1 October 2004

2. De Saro, R., Weisberg, A., Craparo, J., "In Situ, Real Time Measurement of Aluminum, Steel, and Glass Melt Chemistries Using Laser Induced Breakdown Spectroscopy", 2005 ACEEE Summer Study on Energy Efficiency in Industry, West Point, NY July 19-22, 2005

3. Craparo, J., Weisberg, A., De Saro, R., "Measurement of Batch and Cullet Using Laser Induced Breakdown Spectroscopy", $66^{\text {th }}$ Conference on Glass Problems, The American Ceramic Association, A John Wiley and Sons, Inc. October 24-26, 2005

A world wide patent has been issued - Patent number US 6,784,429 B2. In addition, a considerable amount of know-how and trade secrets have been developed. This includes ERCo's C-MORE techniques.

A software package has been developed that uses ERCo's C-MORE techniques and is provided with the LIBS System.

ERCo's website provides information on its varied LIBS applications. 


\section{Conclusions}

ERCo has demonstrated the potential of LIBS technology to provide information to glass manufacturers that has never before been available. LIBS has been used to accurately and reliably measure the chemistry of glass raw materials. The same method can be used to measure mixed batch, both on and off line. This information can be a valuable tool in process control to more precisely control the batch ingredients and to quantitatively measure batch homogeneity.

Preliminary laboratory measurements have shown that LIBS analysis can be potentially used to measure the chemical composition of molten glass at any depth and location insitu and in real time. Access to this information will allow glass manufacturers to better understand their process by providing a spatial-temporal map of conditions inside of a furnace. In addition, problems with glass chemistry and homogeneity can be identified in the furnace so that corrective action can be taken before the glass is formed into the final product.

We have also shown that LIBS can be used in glass recycling to identify and sort various types of cullet. LIBS has an advantage over optical color sensors because it can be used to identify contaminants in the cullet stream that are similar in appearance, but different in chemistry from the desired cullet types. 